American Journal of Applied Sciences 4 (3): 181-183, 2007

ISSN 1546-9239

(C) 2007 Science Publications

\title{
Monitoring System for Uninterruptible Power Supply
}

\author{
S.A.Z. Murad, M.N.Md. Isa and N.A. Rahman \\ School of Microelectronic Engineering, Northern Malaysia University College of Engineering \\ Kompleks Pusat Pengajian KUKUM, 02600 Jejawi, Perlis, Malaysia
}

\begin{abstract}
In industrial process today, reliability of equipment is very important. Power supply must be able to cater the need of industrial process. In case of power failure, backup power supply system must be able to support the main process plant. This is to ensure smooth operation and product quality. In order to do this, uninterruptible power supply (UPS) system can be used to ensure the reliability, stability and consistency of the entire system. This UPS system must be monitored in order to enable them to react accordingly in response to a fault or power failure. In this project, monitoring system for UPS was designed by using visual basic (VB) to provide a safe and constant $12 \mathrm{~V}$ DC supply in the case of power disruption. The main power supply, $240 \mathrm{~V}$ AC was converted to $12 \mathrm{~V}$ DC as output voltage and a battery will be used as part of the backup system. This system will be able to control the source of power which offers power from LIVE line or power from BATTERY line. The main output voltage was $12 \mathrm{~V}$ DC and the battery level will be monitored using GUI software created using VB.
\end{abstract}

Key words: Backup power supply, power failure, uninterruptible power supply, UPS monitoring system, visual basic

\section{INTRODUCTION}

Power back-up system is essential and has been used by industries all over the world to ensure their machines or equipments operation running smoothly without having the effect of power disruption. Therefore, the power back-up system is very important to make sure that the overall system work properly. There are often cases that the power back-up system do not work properly when needed and this failure caused losses in term of time and money to industries. A system that be able to monitor this power back-up system can detect any abnormal activities occurred to the system. In addition, the system can prevent any fault that may affect the whole operations.

UPS systems have enabled the improvement of power source quality, providing clean and uninterruptible power to critical loads such as industrial process controls, computers, medical equipment, data communication systems and protection against power supply disturbances or interruptions $s^{[1-3]}$. UPS provides stable supply to the system in the present or absence of the input supply ${ }^{[4]}$. It is important for the UPS system to be able to take over immediately that full load in power outage or out-of-tolerance situation to avoid any data loss, uncontrolled system shut-down or malfunctioning of the device ${ }^{[5]}$. Commonly, the UPS topology can be classified as off-line UPS, line interactive UPS and online UPS. The three topologies were discussed in details in $^{[2-6]}$.

Corresponding Author:

S.A.Z. Murad, School of Microelectronic Engineering, Northern Malaysia University College of Engineering, Kompleks Pusat Pengajian KUKUM, 02600 Jejawi, Perlis, Malaysia, Tel: 604-979 8432, Fax: 604-979 8305
This study presented on-line UPS monitoring rectifier, charger, battery and static transfer switch. Under normal line conditions, the load is directly supplied from the live line as shown in Fig. 1. After power failure, a battery continues supplying power to the load. Batteries are also available charged, as necessary when line power is available. The monitoring system using Microsoft Visual Basic is designed to monitor the constant 12VDC supply from live line and from the battery when power failure is occurred. The prototype of on-line UPS is designed and output voltage is monitored using Graphical User Interface (GUI) software in order to monitor the overall system.

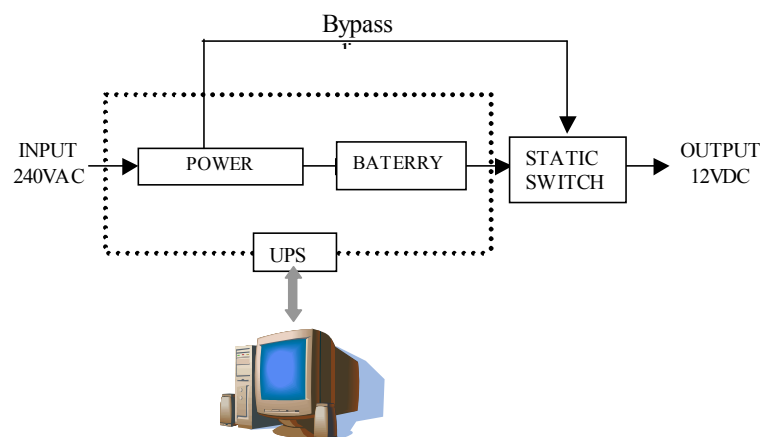

Fig. 1: Block diagram of on-line UPS system with visual basic. The on-line consists of a 
Design method: A simple UPS is designed by using transformer, 1N4001 diodes, capacitors and 7812 IC regulator to produce $12 \mathrm{~V} \mathrm{DC}$ voltage. The output

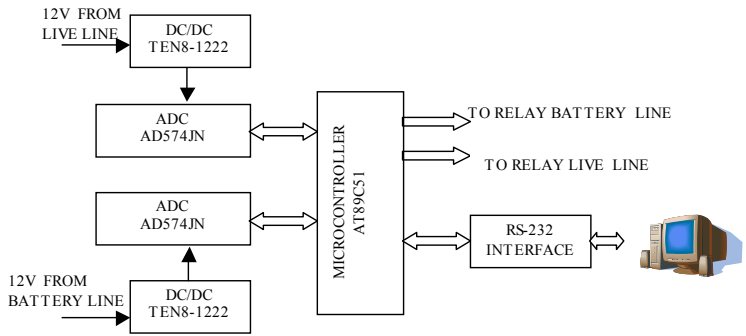

Fig. 2: Block diagram for monitoring system

voltage is supplied to the live line output. The $12 \mathrm{~V}$ DC is then connected to $7805 \mathrm{IC}$ regulator to produce $5 \mathrm{~V}$ DC voltage. This voltage will be used by microcontroller and others components that required $5 \mathrm{~V}$ DC voltage. The $5 \mathrm{~V}$ circuit consisted of 7805 IC regulator that regulates the $12 \mathrm{~V}$ voltage from the main circuit to $5 \mathrm{~V}$ voltage level. There are also $12 \mathrm{~V}$ DC which is supplied from the battery as a backup.

The AT89C51 8-bit microcontroller with $4 \mathrm{~K}$ bytes flash is used to control the overall system. This device is manufactured using Atmel's high density nonvolatile memory technology and allows the program memory to be reprogrammed in system. The DC-to-DC converter that maintains $\pm 12 \mathrm{VDC}$ output with the input range between 9VDC to 18VDC is designed using TRACOPOWER TEN8-1222. The output voltage is then supplied to A/D converter AD574JN that operates in unipolar operation. The AD574JN conversion process is controlled by the microcontroller.

The microcontroller consists of Port 0 , Port 1 , Port 2 and Port 3. Port 0 is connected to AD574JN in orders to control the converter and also connected to relays, controlling the line switching. Port 1 and Port 2 is connected to AD574JN as an input to convert data by A-to-D converter. At Port 3, only pin 10 and pin 11 were used to transmit and received data. Furthermore, the microcontroller is connected to computer by using RS-232 interface. The RS-232 interface circuit consisted of a MAX232 and DB9 female connector. The relays are connected to battery line and live line to perform as a line switching during the interrupt. The hardware will communicate with visual basic software to monitor and control UPS system as shown in Fig. 2.

\section{RESULTS}

The on-line UPS of the system consists of four main components which are power supply circuit, microcontroller circuit, relays circuit and converters circuit as shown in Fig. 3. The components were constructed separately so that the circuit is easy to troubleshoot. The power supply circuit is connected to main source $240 \mathrm{~V}$ AC to produce $12 \mathrm{~V}$ DC voltage. Then, the on-line UPS is connected to the computer to monitor the overall system. The monitoring system for
UPS is shown in Fig. 4. The GUI for the system which is UPS Workbench V1.0 was created using visual basic

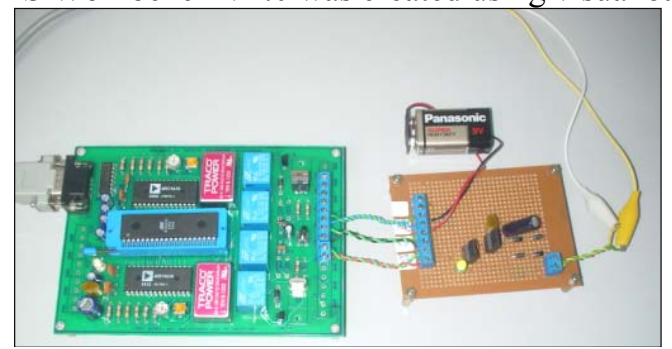

Fig. 3: On-line UPS

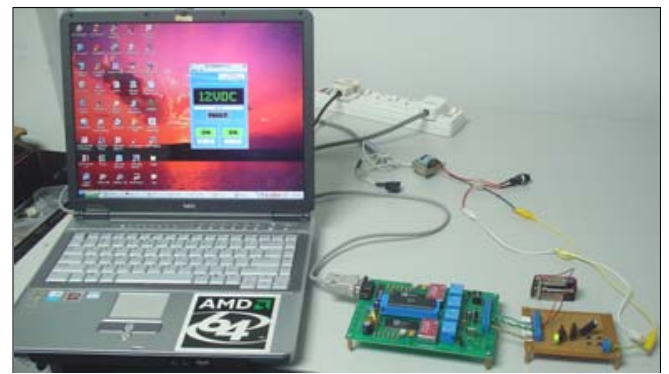

Fig. 4: Monitoring system for UPS prototype

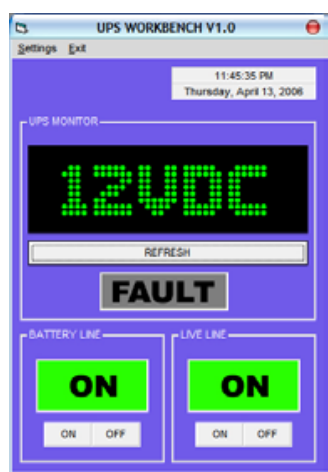

(a)



(b)

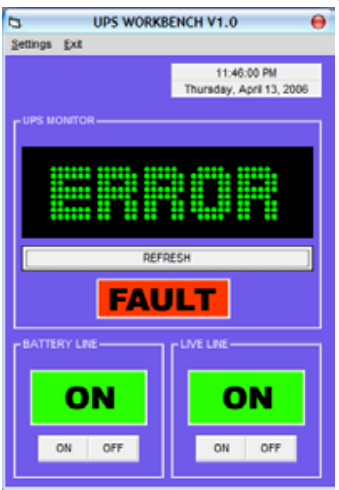

(c)

Fig. 5: Output voltage monitoring results. (a) From live line. (b) From attery line. (c) Power failure for both lines 
will communicate with the microcontroller and monitor the result as shown in Fig. 5a. The UPS interface indicated $12 \mathrm{~V} \mathrm{DC}$ from the live line. Furthermore, the power disruption was created by disconnecting the power line, the system monitor the output voltage at battery line which is $9 \mathrm{~V} \mathrm{DC}$ as shown in Fig. 4b. For the testing purpose, the $9 \mathrm{~V} \mathrm{DC}$ battery is used to make sure both live line and battery line is worked properly. When there is an error occurred, for example both lines have no power, the ERROR and FAULT indicator will appear as shown in Fig. 5c.

\section{CONCLUSION}

It has been shown that the UPS system can be monitored using visual basic. The $12 \mathrm{~V}$ DC voltage from live line is indicated on the main interface on the screen. When the failure occurred on the live line, the voltage level form the battery is appeared on the screen. Furthermore, when there is an error occurred on the system, the ERROR and FAULT indicator will appear on the screen. Therefore, the on-line UPS power from live line or battery line and the overall system will be able to monitor by visual basic is presented.

\section{ACKNOWLEDGEMENTS}

The authors wish to express our appreciation to the support and contributions from those who assist in this research especially Kolej Universiti Kejuruteraan Utara Malaysia (KUKUM) for providing the short term research grant (9001-00034) that enabled the production of this article.

\section{REFERENCES}

1. Oliveira da Silva, S.A., P. Donoso-Garcia, P.C. Cortizo and P.F. Seixas, 2004. A line-interactive UPS system implementation with series-parallel active power-line conditioning for three-phase, four-wire systems. Electrical Power \& Energy Systems, 26: 399-411.

2. Farrukh, K. and T.G. Habetler, 1998. A novel online UPS with universal filtering capabilities. IEEE Trans. on Power Electronics, 13: 3.

3. Liang, T.J. and J.L. Shyu, 2004. Improve DSPcontrolled online UPS system with high real output power. IEE Proc. Online, Electr. Power Appl., 151: 1.

4. Sekh, C. and K. Chawla, 2002. EMC evaluation \& analysis of UPS. Proc. INCEMIC 2001-2002, pp: 37-42.

5. Woojin, C., Jo.W. Howze and P. Enjeti, 2005. Fuel-cell powered uninterruptible power supply systems: Design considerations. J. Power Sources, 19.

6. Matthew, S.R., J.D. Parham and M.H. Rashid, An Overview of Uninterruptible Power Supplies. IEEE Proc., pp: 159-164. 